\title{
Citrate- and glycerol triesters as novel dual-functional dispersants and plasticisers for ceramic processing
}

Foghmoes, S.; Klemensø, T.; Brodersen, K.; Bentzen, J. J.; Della Negra, M.

Published in:

Ceramics International

Link to article, DOI:

10.1016/j.ceramint.2018.02.121

Publication date:

2018

Document Version

Peer reviewed version

Link back to DTU Orbit

Citation (APA):

Foghmoes, S., Klemensø, T., Brodersen, K., Bentzen, J. J., \& Della Negra, M. (2018). Citrate- and glycerol triesters as novel dual-functional dispersants and plasticisers for ceramic processing. Ceramics International, 44(8), 9132-9139. https://doi.org/10.1016/j.ceramint.2018.02.121

\section{General rights}

Copyright and moral rights for the publications made accessible in the public portal are retained by the authors and/or other copyright owners and it is a condition of accessing publications that users recognise and abide by the legal requirements associated with these rights.

- Users may download and print one copy of any publication from the public portal for the purpose of private study or research.

- You may not further distribute the material or use it for any profit-making activity or commercial gain

- You may freely distribute the URL identifying the publication in the public portal 


\section{Citrate- and glycerol triesters as novel dual-functional dispersants and plasticisers for ceramic processing}

S. Foghmoes ${ }^{1}$, T. Klemens $\varnothing^{2}$, K. Brodersen, J. J. Bentzen and M. Della Negra

Department of Energy Conversion and Storage, Technical University of Denmark, Frederiksborgvej 399, DK-4000 Roskilde, Denmark

\section{Abstract}

Short chained triesters of glycerol and citric acid were systematically investigated as novel dual-functional dispersants and plasticisers for use in ceramic processing. Additional systematic studies on a series of diesters having structural similarities with the citrate and glycerol triesters were performed to further assess the significance of specific functional groups for the stabilisation of suspensions.

The overall purpose of this work consists in simplifying the formulation for ceramic processing slurries while at the same time limiting the environmental impact and toxicity. The use of multifunctional additives reduces the risk of unwanted interactions between different components. Additionally, the possible use of one additive in more than one role opens the opportunity for an overall reduction in the number and amount of chemicals and therefore reduction of costs and risks.

For the citrate ester candidates, different alkoxy groups were tested as well as the acetylation on the hydroxyl group. The glycerol esters differed by the length of the carboxylic chain.

Especially triethyl and tributyl citrate are proposed as promising dual-functional additives for ceramic processing. Specifically, for triethyl citrate the dual-function was finally demonstrated by producing a dense piece of 8YSZ through tape casting and subsequent sintering.

Keywords

Ceramic processing; plasticisers; dispersants; toxicity; slurry formulation

1 Corresponding author, Tel.: +45 4677 5689; fax: +45 4677 5858. E-mail address: sqfo@dtu.dk

2 Present address: Høiberg A/S, St. Kongensgade 59 A, 1264 Copenhagen K, Denmark 


\section{Introduction}

Tape casting is a well-known ceramic processing technique for the formation of films for e.g. capacitors (1), proton (2) or oxygen (3) ion conducting membranes and solid oxide fuel cells (SOFCs) (4). Dry thicknesses of $\approx 10$ to $\approx 400 \mu \mathrm{m}$ are in all cases readily achieved.

A slurry for tape casting usually contains a multitude of additives, each with a specific function, including a solvent (usually an azeotropic mixture), a dispersant, a polymeric binder and a plasticiser besides the ceramic powder to be processed $(5,6)$. Sometimes further additives such as wetting agents, homogenisers and/or antifoaming agents are also needed to fine-tune a slurry.

Such a complicated mixture, does from a macroscopic point of view, entail a delicate balance between the particle size distribution (PSD), the viscosity, the shape stability of the green body, the sintering shrinkage and the final density of the sintered body. Often compromises have to be made in the final formulation such as a compromise between dispersant, binder and solids content with shape instabilities observed at low solids content and crack initiation observed at high solids content (7).

In order to fine-tune the microstructure pore formers can be added thus modifying the overall porosity, the pore size distribution, the pore orientation and/or the overall shrinkage $(3,8,9)$. The sintering temperature can be modified by adding sintering additives thereby also altering the shrinkage profile and the final grain size $(10,11)$.

The many additives does, from a microscopic point of view, induce a risk of unwanted cross interactions including competitive adsorption $(12,13)$ or binder crystallization and plasticiser exsolution (14).

Formulation work thus requires considerable attention with some effects, such as slurry stability, originating from interactions on a molecular level and others, such as total sintering shrinkage, originating from bulk effects such as the total amount of combustible material added.

Additionally several of the additives, including many of the commonly used solvents and plasticisers, are toxic and thus it is desirable to find environmentally more friendly replacements.

The primary aim of this paper is therefore to substitute toxic additives while at the same time introducing novel dual-functional additives in order to limit the overall number of 
additives and thereby the number of unwanted interactions. This could lead to a subsequent decrease in the total volume of additives used and reduce costs. At the same time, the better packing of the green ceramic component (due to less organics, without compromising stability) will decrease the sintering shrinkage and/or reduce sintering temperature.

Examples of multi-functional processing additives are, however, limited in literature. The use of cardanol as a dual-function dispersant and plasticiser in apolar solvents is documented (15) while a number of polymers are described as having both binder and dispersant functionalities $(3,16,17,18)$.

Many conventional solvent systems, such as azeotropic mixtures of toluene, trichloroethane, xylene or 2-butanone with ethanol $(5,18,19)$, are increasingly unwanted due to their harmful properties making pure ethanol or isopropanol interesting options for non-aqueous systems $(14,20)$. The binder, plasticisers and dispersants used in this work are therefore selected to be soluble in ethanol.

Ortho-phthalates, such as dibutyl phthalate (DBP), have been extensively used as plasticisers but these are also increasingly unwanted and less toxic alternatives have received an increased focus for ceramic processing $(14,20,21,22)$. Several short chained triesters, based on glycerol and citric acid, have previously been described as plasticisers: triacetin for starch ester films (23); triacetin, triethyl citrate, tributyl citrate, and tributyl 2acetylcitrate for cellulose acetate (24); and triethyl 2-acetylcitrate, tributyl 2-acetylcitrate and tributyl citrate for films of starch and poly(lactic acid) (25).

Based on the general plasticising properties for a number of short chained glycerol and citrate esters and on the dispersing properties of citric acid in water $(26,27)$ and of long chained citrate esters in non-polar solvents $(28,29)$, this work examines a group of short to medium chained glycerol and citrate esters for the desired dual-functional properties in ethanol offering lower environmental impact and a simpler formulation.

In order to show the viability of the idea, the effect of a series of citrate esters (triethyl citrate, tributyl citrate, triethyl 2-acetylcitrate and tributyl 2-acetylcitrate) and a series of glycerol esters (triacetin, tributyrin and trioctanoin) were investigated for their dispersing properties on yttria stabilised zirconia (YSZ) in ethanol. This was accomplished by assessing PSD, sedimentation speed as well as the final packing of the particles after sedimentation. The stabilisation mechanism was investigated through the measurement of 
the suspension zeta potential allowing for a differentiation between steric and electrostatic stabilisation.

The plasticising effect on polyvinyl butyral (PVB), also introducing various amounts of a polyethylene glycol (PEG) as a co-plasticiser, were assessed from dried binder systems prepared using ethanol as a solvent. The use of a co-plasticiser can be desirable as different classes of plasticisers acts differently and induce slightly different properties to the final green tape $(6,30)$.

Finally a green tape was produced using triethyl citrate to demonstrate the applicability of these dual-functional additives.

A number of diesters namely, diethyl succinate, diethyl fumarate, diethyl maleate, diethyl malate and diethyl tartrate, were additionally investigated in order to further assess the functional groups required for obtaining a proper dispersing effect. This was done both in order to be able to predict optimal molecules for further testing but also to complement the limited literature on the polar screen theory which describes the ability of some small polar molecules to induce good stabilisation through an electrostatic mechanism (31, 32, 33). A previous study, in a similar system, has additionally shown a strong correlation between the number and type of groups being present and the resulting dispersing properties (34). Several succinates and maleates have previously been reported as plasticisers for PVC (35), while dibutyl maleate is a plasticiser for PVB (14) and diethyl tartrate a plasticiser for keratin (36) indicating possible dual-function properties for some of the studied diesters as well.

\section{Experimental procedure}

\subsection{Materials}

The powders used were TZ3Y and TZ8Y from TOSOH while the solvent was $99.9 \%$ ethanol from CCS Healthcare.

As binder a PVB polymer was used. Figure 1 gives structure and additional specifications.

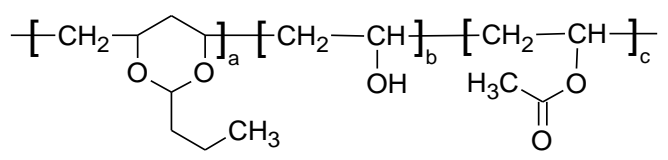


Figure 1: Polyvinyl butyral with $M w=55 \mathrm{k} \pm 5$ $\mathrm{k}, \mathrm{a}=78.0 \pm 3.0 \mathrm{~mol} \%, \mathrm{~b}=19.5 \pm 1.5 \mathrm{~mol} \%$ and $\mathrm{c}=2.5 \pm 1.5 \mathrm{~mol} \%$.

As possible dual-function dispersants and plasticisers the following chemicals were obtained from Sigma-Aldrich: triethyl citrate $(\geq 99 \%)$, tributyl citrate $(\geq 97.0 \%)$, triethyl 2acetylcitrate $(99 \%)$, tributyl 2-acetylcitrate $(\geq 98 \%)$, triacetin $(99 \%)$, tributyrin $(97 \%)$ and trioctanoin $(\geq 99 \%)$.

The general structure of these citrate and glycerol esters can be seen in Figure 2.

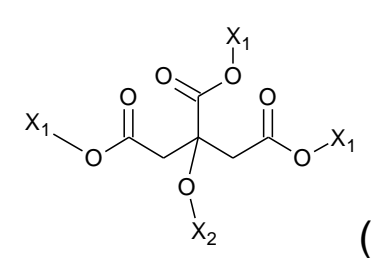

(a)<smiles>[Y]C(=O)OCC(COC([Y])=O)OC([Y])=O</smiles>

Figure 2: Chemical structures for (a) the citrate esters with $X_{1}$ all ethyl or butyl groups and $X_{2}$ hydrogen or acetyl group (b) the glycerol esters with $Y_{1}$ all ethyl, butyl or octyl groups.

For a further investigation of the influence of the type, position and number of substituents the following diesters were obtained from Sigma-Aldrich: Diethyl succinate $(99 \%)$, diethyl fumarate $(98 \%)$, diethyl maleate $(97 \%)$, diethyl malate $(\geq 97 \%)$ and diethyl L-tartrate $(\geq 99 \%)$ The structure of these diesters can be seen in Figure 3.

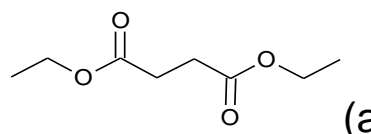

(a)<smiles>CCOC(=O)CC(O)C(=O)OCC</smiles>

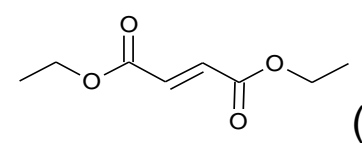

(b)

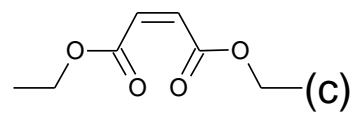

(d)

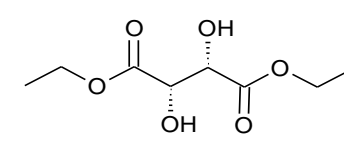

(e)

Figure 3: Chemical structures for (a) diethyl succinate, (b) diethyl fumarate, (c) diethyl maleate, (d) diethyl malate and (e) diethyl tartrate.

As a co-plasticiser polyethylene glycol (PEG 600) was obtained from Sigma-Aldrich. 


\subsection{Assessment of plasticising properties}

The plasticising properties of each candidate were assessed by mixing it with a polymeric binder (PVB) in ethanol, using various ratios, and then dry the resulting binder mixtures before further examination. Upon drying, the droplets were investigated for transparency, sweating and mechanical strength. An opaque appearance indicates binder recrystallization while sweating indicates plasticiser exsolution. Both behaviours are indicative of chemical incompatibilities and are thus unwanted. The mechanical properties were assessed manually with a DBP based system as a reference. A detailed description of the procedure can be found elsewhere (14).

\subsection{Assessment of dispersing properties}

Slurries for assessment of dispersing properties were prepared by dissolving $4 \mathrm{~g}$ of dispersant in $250 \mathrm{~g}$ of ethanol in a $1 \mathrm{~L} \mathrm{PE}$ bottle. $100 \mathrm{~g}$ of TZ3Y was then added and the slurry was milled for 2 days at approx. $200 \mathrm{rpm}$ using $1 \mathrm{~kg}$ of $3 / 8$ inch zirconia milling beads. A sample without added dispersant was used as a reference.

The composition of these samples was chosen as a compromise between having a solid load comparable to the tape casting conditions while still being able to include the reference suspension without added dispersant. In fact, at higher solid load it was impossible to wet the ceramic powder without introducing a dispersant.

The PSD was determined for each sample immediately after milling and a sample of approximately $20 \mathrm{ml}$ was extracted for measurement of sedimentation speed and final packing. The remaining sample was used for measurement of zeta potential. The combination of these techniques has previously been reported as a good combination to assess the degree and mechanism of stabilisation (37).

\subsubsection{Sedimentation speed and final packing}

Sedimentation studies were performed with a Turbiscan Lab (Formulaction, France) using the Turbisoft software version 2.1.0.52. Essentially the setup follows the position of the sedimentation front as a function of time with high precision and this can be used to evaluate the overall stability of a suspension as described elsewhere (37).

\subsubsection{Zeta potential}


The zeta potential of the YSZ suspensions was determined by measuring the Electrokinetic Sonic Amplitude (ESA) with a ZetaProbe Analyzer (Colloidal Dynamic LLC, USA). The measurement can be used to assess the extent of electrostatic stabilisation as described elsewhere (37).

\subsubsection{Particle sizing}

A Beckman Coulter LS 13320 with a measurement range of $0.04-2000 \mu \mathrm{m}$ was used to analyse the PSDs.

All PSDs were evaluated using at least 3 samplings to ensure good data quality while also assessing the effect of different levels of obscuration and thereby different sensitivities at different size ranges (38).

Measurements after binder addition were performed as a quality control to ensure that the binder system selected for tape casting does not significantly affect the slurry stability. This control is critical for these dual-functional additives as the amount needed for the plasticising effect is larger than that needed for the dispersing effect possibly inducing reflocculation upon the addition of the binder system which contains additional dual-role additive. No such re-flocculation was observed.

\subsection{Tape casting, sintering and post examination of sintered samples}

A tape was made to demonstrate the use of a dual-function additive for a real application by mainly substituting the dispersant (PVP 10k) and the plasticiser (Pycal 94) with a dualrole candidate in a 1:1 ratio relative to an earlier reported system (14). The tape casting slurry was prepared by dissolving $3 \mathrm{~g}$ of triethyl citrate in $65 \mathrm{~g}$ of ethanol in a $1 \mathrm{LPE}$ bottle. Upon dissolving the dispersant, $150 \mathrm{~g}$ of TZ8Y was added and the slurry was milled for 3 days at approx. $200 \mathrm{rpm}$ using $1 \mathrm{~kg}$ of $3 / 8$ inch zirconia milling beads. $78 \mathrm{~g}$ of a premixed binder system was then added and mixed in for the following 24 hours. The binder was mixed according to the ratio later identified as primary candidate.

The viscosity was subsequently adjusted in order to obtain a viscosity suitable for tape casting. The slurry was finally filtered using a $37 \mu \mathrm{m}$ filter and de-aired prior to tape casting. 
A double doctor-blade system was used for tape casting with a casting gap of $1000 \mu \mathrm{m}$ and the tape was allowed to dry at slow ventilation overnight inside the tape caster before further handling.

An additional slurry containing as much as $12 \mathrm{~g}$ of dispersant during the milling step was prepared to show that no flocculation occurs at high dispersant concentrations comparable to that needed for good plasticisation.

A slurry with no dispersant and $90 \mathrm{~g}$ of solvent was prepared to assess the PSD without any dispersant. The larger amount of solvent was needed to wet the powder in this case.

After tape casting, samples with a diameter of $40 \mathrm{~mm}$ were sintered. The samples were slowly heated with $0.25^{\circ} \mathrm{C} / \mathrm{min}$ to $600{ }^{\circ} \mathrm{C}$, followed by a binder burnout for 4 hours at 600 ${ }^{\circ} \mathrm{C}$. The samples were then heated with $1^{\circ} \mathrm{C} / \mathrm{min}$ to at least $1250{ }^{\circ} \mathrm{C}$, followed by sintering for a maximum of 12 hours. The samples were finally cooled to room temperature with 100 ${ }^{\circ} \mathrm{C} / \mathrm{h}$.

A sintered sample was mounted in epoxy, polished until a $1 / 4$ micron diamond suspension and coated with carbon. The sample cross section was investigated by scanning electron microscopy (SEM) applying a Zeiss Merlin microscope equipped with an angle selective backscattered detector. The working distance was set to $3.8 \mathrm{~mm}$, the acceleration voltage to $19 \mathrm{kV}$ and the probe current to $2.0 \mathrm{nA}$ for an enhanced electron channelling contrast between different crystallographic orientations (39).

3. Assessment of environmental and health impact of the selected plasticisers

Ortho-phthalates have recently become unwanted as some of them exhibit a number of unwanted health effects. As an example DBP is in the pre-registration process under $\mathrm{REACH}$ and it "may damage the unborn child and is suspected of damaging fertility and is very toxic to aquatic life" (40). It has also been included in the European Chemicals Agency's "Candidate List of substances of very high concern for authorisation" with the reasons "Toxic for reproduction" and "Endocrine disrupting properties" (41) as well as in the "Authorization List" (42)

To avoid replacing ortho-phthalates with equally problematic alternatives, some effort was used to assess possible environmental and health issues with the chemicals proposed. 
Tributyrin (43), trioctanoin (44) and triethyl 2-acetylcitrate (45) are in the pre-registration process under REACH with triethyl 2-acetylcitrate listed as "may cause an allergic skin reaction."

Triacetin (46), triethyl citrate (47), tributyl citrate (48) and tributyl 2-acetylcitrate (49) are all pre-registered under REACH with CLP notifications identifying issues regarding serious eye damage for tributyl citrate.

Triacetin (50), trioctanoin (51), triethyl citrate, tributyl citrate (52), triethyl 2-acetylcitrate and tributyl 2-acetylcitrate (53) have been evaluated for use in cosmetics and have been found safe for use. Triacetin (50) and triethyl citrate (52) are additionally stated as being "in general recognised as safe direct food additives by the Food and Drug Administration (FDA)". Triethyl 2-acetylcitrate did, on the contrary, show strong skin sensitisation at larger concentrations (53).

All in all, the selected plasticisers are considered to be promising although not entirely harmless alternatives to ortho-phthalates.

\section{Results}

The prepared binder systems were evaluated by qualitative measures: strong (S), weak $(\mathrm{W})$, flexible $(\mathrm{F})$, inflexible $(\mathrm{I})$, opaque $(\mathrm{O})$ and sweating $(\mathrm{SW})$. Strength and flexibility are somewhat interrelated and in general an increase in flexibility will come at the expense of strength resulting in a compromise. Opaqueness and sweating are both indicative of chemical incompatibility and are thus entirely unwanted.

The results from the evaluation of the plasticising properties are presented graphically, for triethyl citrate and tributyl citrate, in Figure 4 and show the compositions of the samples with the qualitative measures indicated next to the compositions. The one or two compositions showing good chemical compatibility as well as a strength and flexibility similar to the DBP-based reference, are marked as "primary candidate" and "secondary candidate", respectively. Triethyl citrate and tributyl citrate are the only candidates displayed here, as they show the best combined properties of slurry stabilisation and tape plasticisation. 


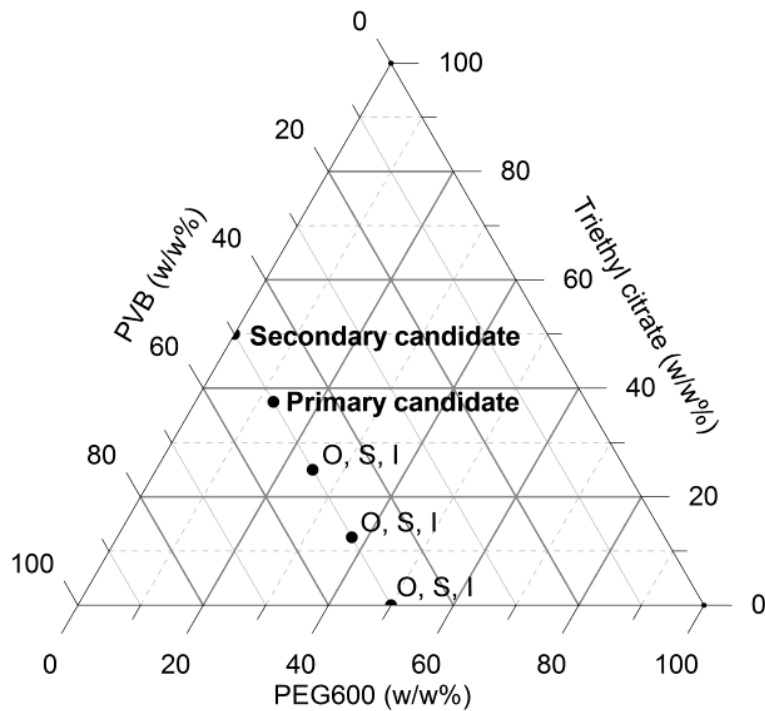

(a)

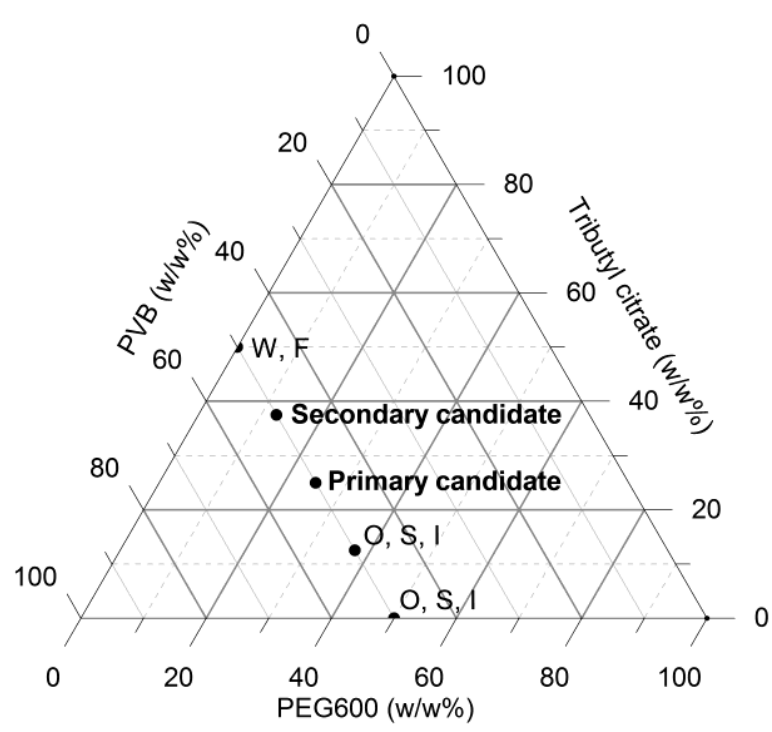

(b)

Figure 4: Plot of tested compositions for (a) triethyl citrate and (b) tributyl citrate. $\mathrm{W}=$ Weak, $\mathrm{F}=$ Flexible, $\mathrm{S}=$ Strong, $\mathrm{I}=$ Inflexible and $\mathrm{O}=$ Opaque.

For triacetin and trioctanoin no usable compositions were found as all the tested ratios showed signs of chemical incompatibility. These two plasticisers are thus considered incompatible with the selected binder.

For the two shown citrates, as well as for triethyl 2-acetylcitrate, tributyl 2-acetylcitrate and tributyrin, compositions were found where no sweating, neither towards the air or the carrier foil interface, or opaqueness were visible, illustrating a rather general compatibility for these short chained triesters with the selected binder.

Figure 5 shows a combined plot of the best evaluated compositions, of all the tested plasticisers, which further helps to define a rather narrow general area for the optimum plasticiser loading for these short chained triesters with the selected binder. 


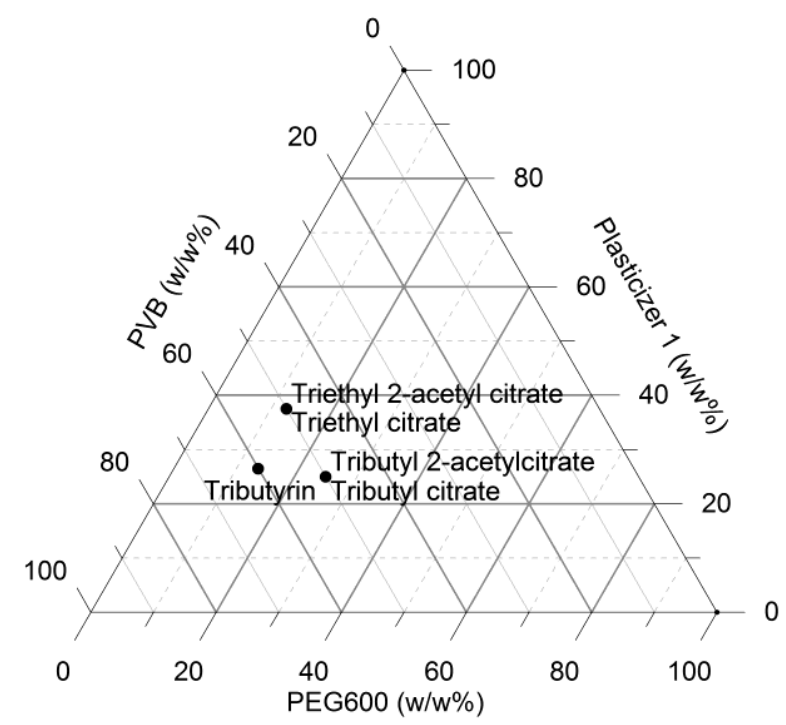

Figure 5: Plot of the optimum composition for a plasticising effect.

In general, there seems to be a need for keeping the amount of the co-plasticiser PEG 600 low as higher loadings result in chemical incompatibilities, seen as binder crystallization and plasticiser exsolution, along with a lack of plasticity consistent with reports on similar binder systems (14).

Regarding the dispersing properties the zeta potential reaches values as high as $\approx 35 \mathrm{mV}$ in the pure YSZ/ethanol system. The repulsion forces and the Debye length are, however, not large enough to provide full stability to sub-micron agglomerates. Similarly, experiments and calculations performed on alumina suspensions in ethanol show that full stability by electrostatic repulsion was obtained only for large zeta potentials $(|\xi|>43$ $\mathrm{mV})(54)$.

Even larger zeta potentials are measured for triethyl citrate and tributyl citrate $(\xi \approx 50$ and $55 \mathrm{mV}$ respectively) while triethyl 2-acetylcitrate and tributyl 2-acetylcitrate have zeta potentials similar to that of the reference $(\xi \approx 35 \mathrm{mV})$ illustrating very good electrostatic stabilisation for the non-acetylated citrates.

The sedimentation profiles and the PSDs, given in Figure 6, confirms that acetylated citrate esters have little stabilising effect pointing at a huge importance of the alcohol group and/or at a steric hindrance induced by the acetylation possibly restricting the approach of the dispersant to the particle surface. Moreover the acetylated citrate esters do not allow for good packing of the ceramic particles, as visible in Figure 6 when the sedimentation 
process reaches the steady state. This parameter is an indication of poor packing in the green body after tape casting (19).
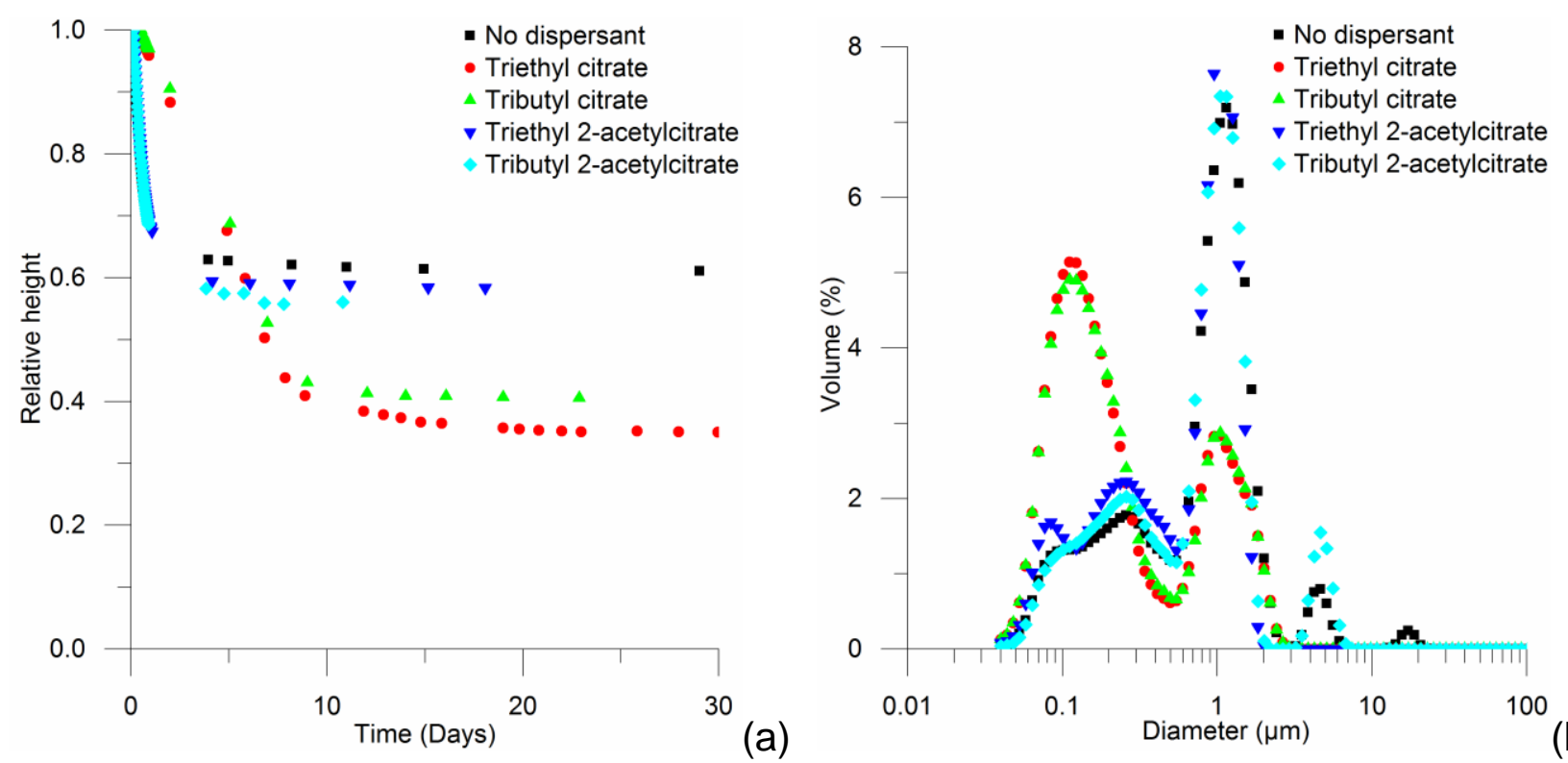

(b)

Figure 6: Sedimentation profiles (a) and PSDs (b) for the tested citrate esters.

The variation of chain lengths (ethyl vs. butyl) does not affect sedimentation rate indicating that the alkyl group length in this case has no key influence on the stabilisation though the somewhat less bulky ethyl group allows for a slightly better final packing.

In the case of glycerol esters a large zeta potential is measured for triacetin $(\xi \approx 55 \mathrm{mV})$ while tributyrin and trioctanoin have zeta potentials similar to that of the reference $(\xi \approx 35$ $\mathrm{mV}$ ) illustrating very good electrostatic stabilisation for the short chained triacetin. The sedimentation profiles and the PSDs, given in Figure 7, confirm a strong dependency of the slurry stability on the chain length, with the short chained triacetin being significantly better performing. 

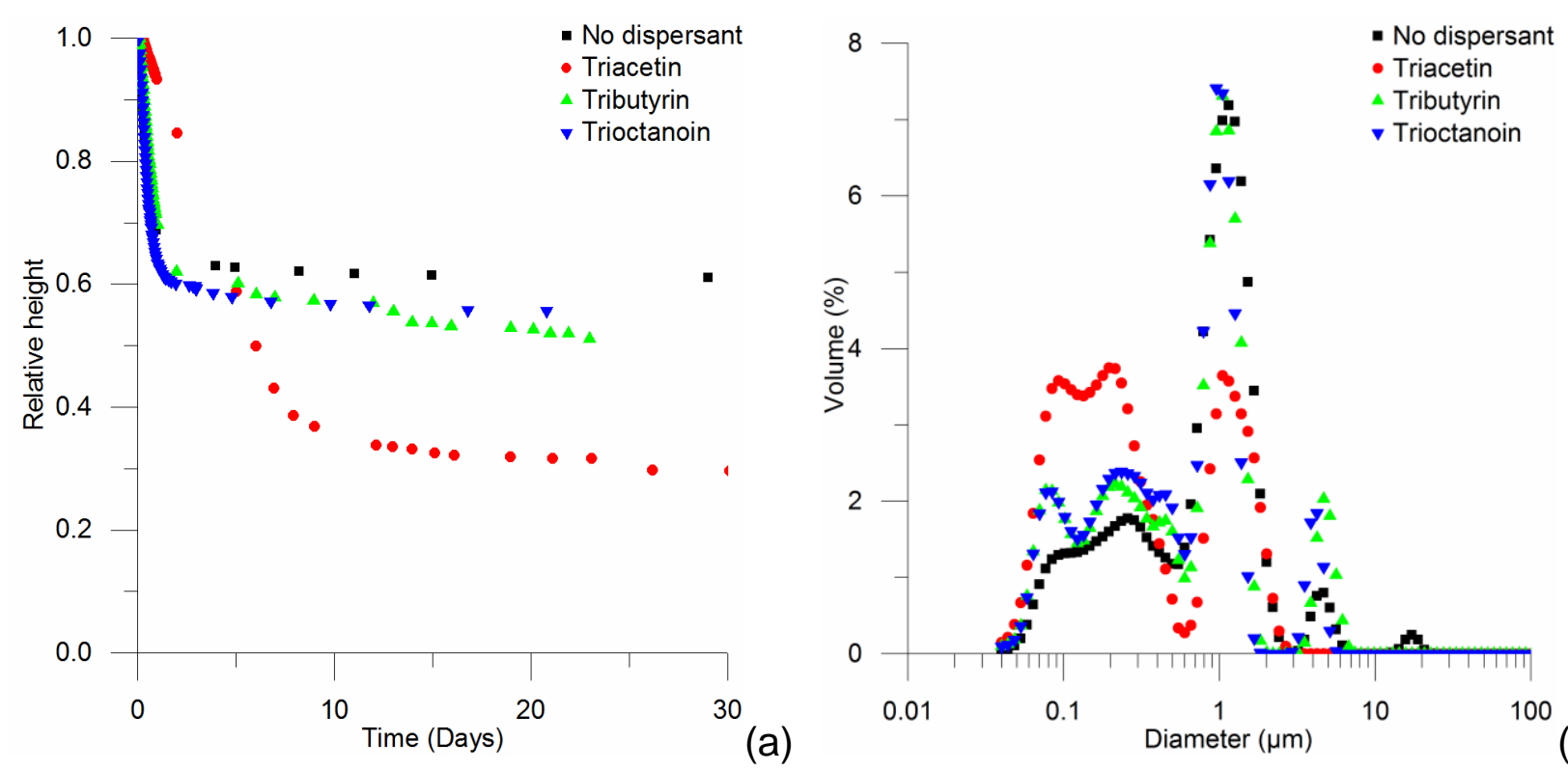

(b)

Figure 7: Sedimentation profiles (a) and PSDs (b) for the tested glycerol esters.

Even though 3YSZ has a high zeta potential in ethanol, wetting of the powder at high solid loading is not possible and de-agglomeration at medium solid loading is not optimal, as visible in the PSD graph. Addition of triethyl citrate, tributyl citrate or triacetin allows fast powder wetting and provides excellent dispersing properties through an enhancement of the already significant zeta potential offering additional electrostatic stabilisation. Tributyrin, trioctanoin, triethyl 2-acetylcitrate and tributyl 2-acetylcitrate all offer very limited or no improvement of the stabilisation. Key parameters, such as the initial sedimentation speed and median particle diameter (D50), have been extracted and collected in Table 1 for direct comparison.

Table 1: Dispersing properties for glycerol and citrate triesters based on key stability parameters: PSD (D10, D50 and D90), zeta potential, relative sedimentation height after 30 days, and initial sedimentation speed.

\begin{tabular}{|c|c|c|c|c|c|c|}
\hline & $\mathrm{D} 10(\mu \mathrm{m})$ & $\begin{array}{l}\text { D50 } \\
(\mu \mathrm{m})\end{array}$ & $\begin{array}{l}\text { D90 } \\
(\mu \mathrm{m})\end{array}$ & $\begin{array}{c}\text { Zeta } \\
\text { potential } \\
(\mathrm{mV})\end{array}$ & $\begin{array}{c}\text { Relative } \\
\text { sediment } \\
\text { height (\%) }\end{array}$ & $\begin{array}{c}\text { Initial } \\
\text { sedimentation } \\
\text { speed }(\mathrm{mm} / \mathrm{h})\end{array}$ \\
\hline No dispersant & 0.13 & 0.97 & 1.72 & 37 & 61 & 0.95 \\
\hline Triethyl citrate & 0.08 & 0.19 & 1.38 & 49 & 35 & 0.12 \\
\hline Tributyl citrate & 0.08 & 0.19 & 1.38 & 55 & 40 & 0.12 \\
\hline Triethyl 2-acetylcitrate & 0.11 & 0.82 & 1.38 & 37 & 58 & 0.83 \\
\hline Tributyl 2-acetylcitrate & 0.14 & 0.91 & 1.62 & 32 & 56 & 0.84 \\
\hline
\end{tabular}




\begin{tabular}{|l|l|l|l|l|l|l|}
\hline Triacetin & 0.08 & 0.24 & 1.51 & 54 & 30 & 0.15 \\
\hline Tributyrin & 0.12 & 0.80 & 1.57 & 39 & 51 & 0.69 \\
\hline Trioctanoin & 0.12 & 0.71 & 1.44 & 37 & 55 & 0.92 \\
\hline
\end{tabular}

The origin of the large zeta potential seems somewhat different from that observed for citric acid in water $(26,27)$, where a negatively charged citrate is adsorped on a positively charged surface inducing strong electrostatic stabilisation.

The stabilisation observed in the present case is, however, not due to the adsorption of charged species such as citric acid. The formation of such species is negligible as degradation of esters is very slow at the tested temperatures and $\mathrm{pH}$ regimes. Additionally such degradation would not allow for the simultaneously demonstrated plasticising effect.

A pure steric stabilisation mechanism were likely the origin of the stabilisation induced by bulky citrate esters in non-polar solvents $(28,29)$ but in the present work especially the ethyl but also the butyl groups are too short to offer significant steric stabilisation.

In the present case the stabilisation is rather obtained through an interaction between the dispersants and the ceramic surface through polar interactions or hydrogen bonding. This interaction induces an enhanced electrostatic charging offering a good electrostatic stabilisation $(31,32,33)$.

In order to further investigate which functional groups that will induce good dispersing properties, the effect on stabilisation was studied by systematically testing a number of chemically rather similar compounds. The diesters diethyl succinate, diethyl fumarate, diethyl maleate, diethyl malate and diethyl tartrate were chosen as they systematically vary the steric orientation of the carboxylate group as well as the total number of alcohols available.

As visible in Table 2, diethyl tartrate induces a very large zeta potential ( $\xi \approx 65 \mathrm{mV})$, diethyl maleate and diethyl succinate both induce intermediate zeta potentials $(\xi \approx 50$ and $45 \mathrm{mV}$ respectively) while diethyl malate and diethyl fumarate have zeta potentials similar to that of the reference $(\xi \approx 35 \mathrm{mV})$ illustrating very good electrostatic stabilisation for diethyl tartrate which has two alcohol groups.

Table 2: Dispersing properties for diesters based on key stability parameters: PSD (D10, D50 and D90), zeta potential, relative sedimentation height after 30 days and initial sedimentation speed. 


\begin{tabular}{|l|c|c|c|c|c|c|}
\hline & $\begin{array}{c}\text { D10 } \\
(\mu \mathrm{m})\end{array}$ & $\begin{array}{c}\mathrm{D} 50 \\
(\mu \mathrm{m})\end{array}$ & $\begin{array}{c}\mathrm{D} 90 \\
(\mu \mathrm{m})\end{array}$ & $\begin{array}{c}\text { Zeta } \\
\text { potential } \\
(\mathrm{mV})\end{array}$ & $\begin{array}{c}\text { Relative } \\
\text { sediment } \\
\text { height }(\%)\end{array}$ & $\begin{array}{c}\text { Initial } \\
\text { sedimentation } \\
\text { speed }(\mathrm{mm} / \mathrm{h})\end{array}$ \\
\hline No dispersant & 0.13 & 0.97 & 1.72 & 37 & 61 & 0.95 \\
\hline Diethyl succinate & 0.09 & 0.50 & 1.61 & 45 & 42 & 1.24 \\
\hline Diethyl fumarate & 0.09 & 0.51 & 1.54 & 35 & 53 & 0.90 \\
\hline Diethyl maleate & 0.09 & 0.29 & 1.54 & 51 & 44 & 0.25 \\
\hline Diethyl malate & 0.09 & 0.33 & 1.48 & 35 & 48 & 0.57 \\
\hline Diethyl tartrate & 0.08 & 0.18 & 1.57 & 64 & 26 & 0.05 \\
\hline
\end{tabular}

The sedimentation profiles and PSDs are shown in Figure 8 supporting the very good stabilisation offered by diethyl tartrate. For diethyl maleate the rather large zeta potential is accompanied by some decrease in sedimentation speed, some improvement in sediment packing and some reduction in the PSD while limited overall effect is observed for diethyl malate, diethyl fumarate and diethyl succinate showing that the intermediate enhancement of the zeta potential provided by diethyl succinate is still insufficient for electrostatic stabilisation in this case.
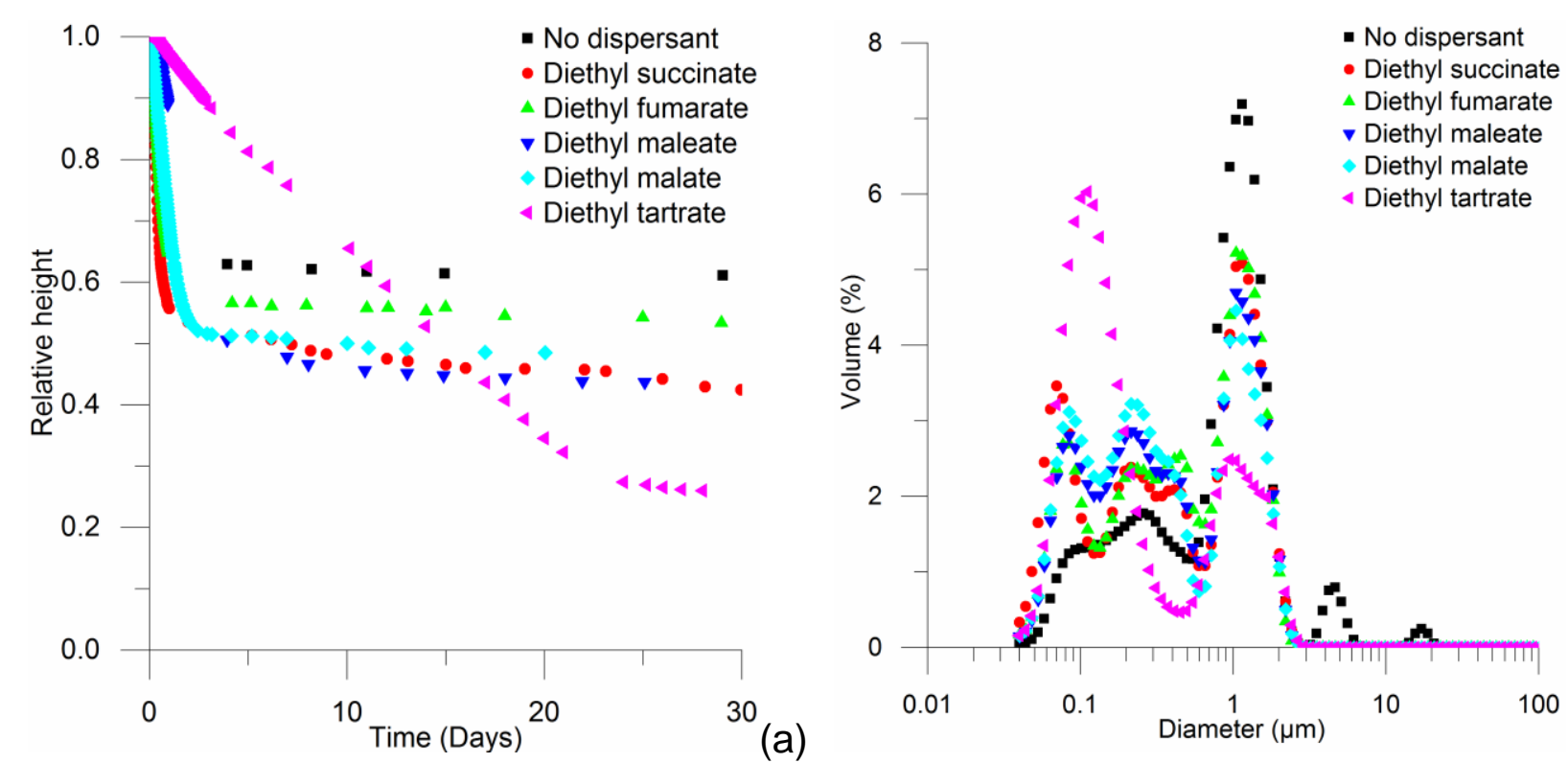

Figure 8: Sedimentation profiles (a) and PSDs (b) for the tested diesters.

As well as for the triesters, the diesters induce stabilisation through an electrostatic mechanism, as witnessed by the increased zeta potentials, and in general all the tested esters have some dispersing properties with triethyl citrate, tributyl citrate, triacetin and diethyl tartrate showing excellent properties, diethyl maleate showing intermediate 
properties and the rest showing weak properties as a combined evaluation of the results obtained with different techniques.

For demonstration of the dual-function action in a real process a thick and dense piece of 8YSZ was produced by tape casting with triethyl citrate acting in a dual-function. Even though the tape is cast with a doctor blade set to $1 \mathrm{~mm}$ the resulting tape is crack free with limited edge curling and no release from the carrier foil altogether indicating little residual stress in the resulting tape (30).

The flexibility and strength of the tape were also suitable for easy handling though a further optimisation of the mechanical properties should be performed using thermomechanical analysis as previously described (14). Such an optimisation should include a focus on the reuse of the dispersant as a plasticiser thereby also reducing the volume of added chemicals.

In the current case dispersant loadings up to at least $8 \%$ does not seem to affect the PSD of actual tape casting slurries as seen in Figure 9.

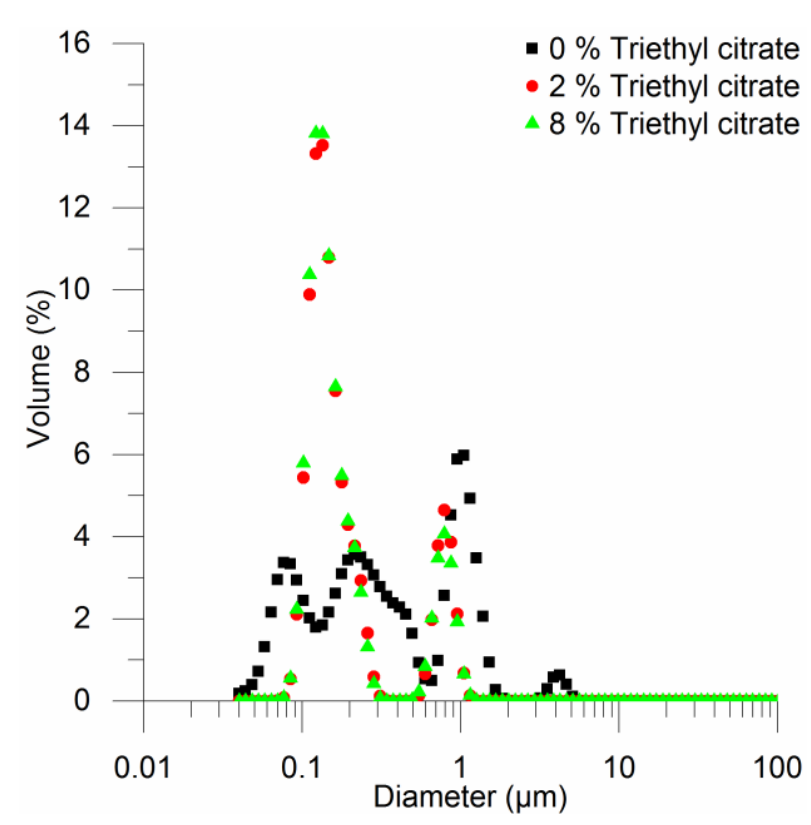

Figure 9: PSDs for tape casting slurries with different concentrations of triethyl citrate as dispersant.

Although the use of a dual-functional additive works in the current case then it is worth considering that dispersants are generally speaking added at lower levels than plasticisers and that the loading needed for a sufficient plasticising effect might in other cases be larger than that inducing re-flocculation. 
When sintering at temperatures in excess of $1250{ }^{\circ} \mathrm{C}$ for up to $12 \mathrm{~h}$, almost completely dense and crack free ceramic specimens can be obtained as demonstrated in Figure 10.
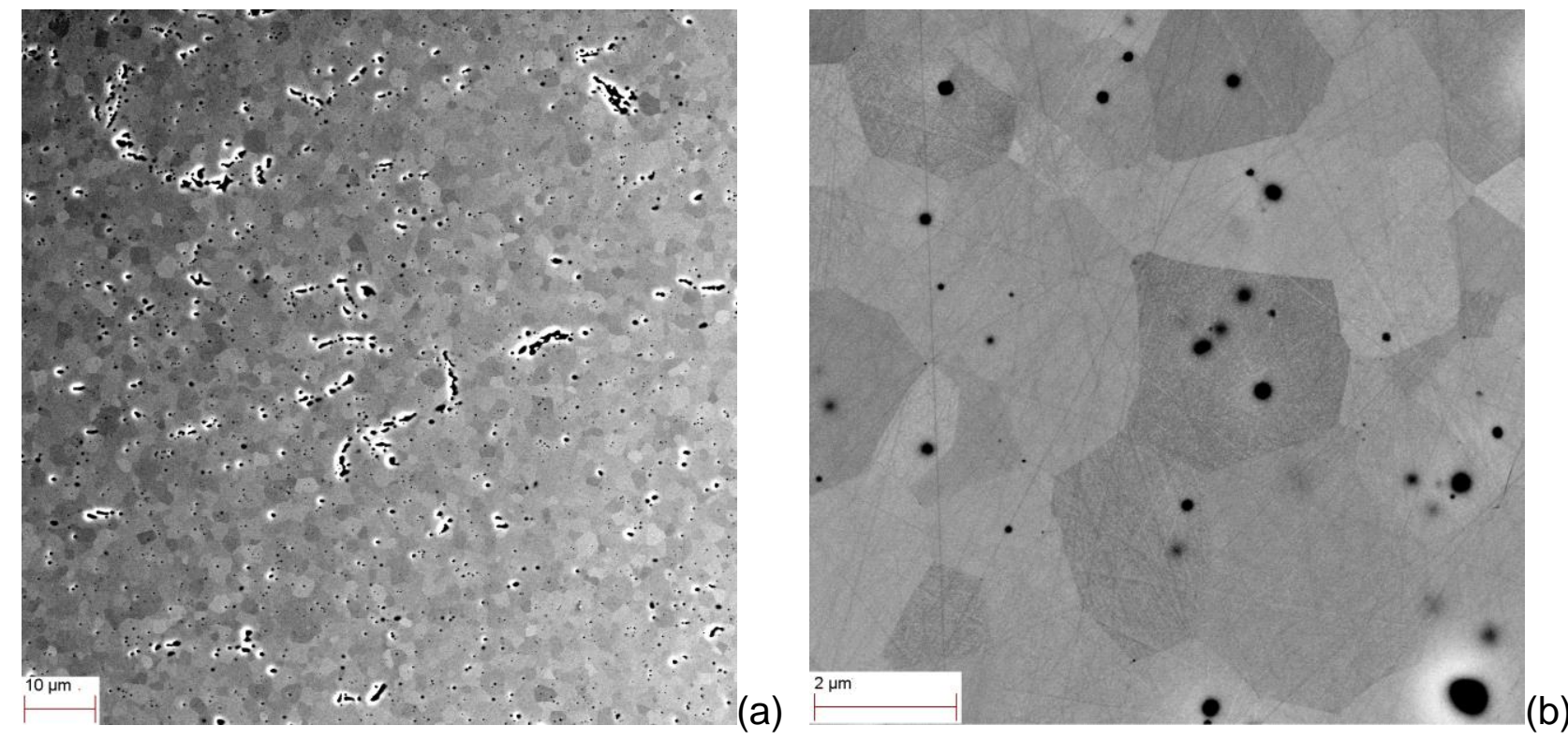

Figure 10: SEM images of sintered dense ceramic produced using a dual-function dispersant and plasticiser.

The remaining porosity is comparable to that obtained with more traditional dispersants such as PVP or PEI (37). The grain sizes are, however, larger ranging from $\approx 0.5$ to $\approx 2$ $\mu \mathrm{m}$.

\section{Discussion}

Since the used dispersants are not ionic other and weaker kinds of interactions must be present at the surface. In terms of a classic description of intermolecular forces there are alcohols which can form strong hydrogen bonds with electronegative elements such as oxygen atoms at the surface. The $\mathrm{C}=\mathrm{O}$ bonds in the esters moieties are also polarised and the resulting dipole can also interact with the surface. Finally the apolar carbon chains can interact through even weaker dispersive forces. This latter interaction is negligible for short carbon chains as in the present case.

As already mentioned the glycerol esters exhibit a behaviour which is differing from those of the citrate esters when varying the chain length.

In the case of the glycerol esters the elongation of the chain from ethyl to the bulkier butyl or even octyl results in much poorer stabilisation. This elongation seems to prevent an 
approach of the dispersant to the particle surface through the increasing bulkiness of the side chains. An approach to the surface also limits the conformational freedom of the side chains causing an increased entropic penalty when elongating them.

In the case of the citrate esters no dependency on the length of the side chains is observed. The contribution of the hydrogen bonds thus seems to be much larger than that of the side chains as the citrate esters are less sensitive to a variation of the length of these side chains. In the case of the acetylated citrate esters the added group sterically prevents the approach to the surface making the acetylated citrates poor dispersants independently of the length of the side chains.

The effect of the presence and position of alcohol and carboxylic acid groups for stabilisation has previously been studied for the stabilisation of alumina in water (34). It was there shown that it in general was favourable to have many of these groups available and positioned so they can interact with the surface simultaneously.

Comparing the citrate esters with the glycerol esters there is an additional effect from the orientation of the ester groups relative to the central carbon chain. A C-COOR configuration is observed in the case of citrate esters while a C-O-COR' configuration is observed in the case of glycerol esters. This changes the conformational freedom at the rather crowded centre of the molecule and thereby also the possible approach of interacting groups.

Comparing diethyl succinate, diethyl fumarate and diethyl maleate it is seen that for diethyl maleate the ester groups are locked in the same direction whereas the diethyl fumarate has them locked in opposite directions and diethyl succinate has free rotation. The different performance of diethyl maleate and diethyl fumarate indicate that the molecules do not adsorp/interact in a planar way on the surface, but rather like a chelate, indicating little interaction through the double bond. Diethyl succinate has free rotation and will for entropic reasons assume a larger range of conformations. The worse performance of diethyl succinate, when compared to diethyl maleate, shows that this entropic penalty is sufficient to prevent good stabilising properties.

Comparing diethyl succinate, diethyl malate and diethyl tartrate it is seen that as much as two alcohol groups are needed to induce proper stabilisation for the diesters.

Altogether many interactions either through the stronger hydrogen bonds or the weaker polarised ester moieties are needed for a sufficient enhancement of the zeta potential. The performance of diethyl succinate vs. diethyl maleate and the performance of triactin vs. 
tributyrin illustrates that the interactions are so subtle that they can be overcome by either entropic contributions and/or small changes in steric hindrance.

\section{Conclusions}

A number of closely related small di- and triesters were investigated for having dualfunction plasticising and dispersing properties.

A dispersing effect was demonstrated on a 3YSZ powder in ethanol through the measurement of PSDs, sedimentation speed and final packing. Based on the measured zeta potentials and the non-ionic nature of the used dispersants a polar screen mechanism, resulting in enhanced zeta potentials, was proposed. The presence of alcohol groups, which can function both as hydrogen bond donors as well as hydrogen bond acceptors, seems to be particularly favourable. Especially diethyl tartrate, triacetin, triethyl citrate and tributyl citrate showed good dispersing properties.

Of these triethyl citrate and tributyl citrate were tested with a PVB binder and showed good plasticising properties in dried binder systems.

For triethyl citrate the dual-function effect was finally demonstrated by successfully tape casting and sintering of a dense piece of 8YSZ.

\section{Acknowledgements}

This work was carried out within the SymSOEC project, supported by the Department of Energy Conversion and Storage, DTU. The authors acknowledge Marianne Nielsen for the tape casting of selected samples and Henrik Paulsen for preparation of samples for microscopy.

1 G. N. Howatt, R. G. Breckenridge and J. M. Brownlow, Fabrication of thin Ceramic Sheets for Capacitors, Journal of the American Ceramic Society, vol. 30 (1947) p. 237242

2 E. Mercadelli, D. Montaleone, A. Gondolini, P. Pinasco and A. Sanson, Tape-cast asymmetric membranes for hydrogen separation, Ceramics International , Vol. 43 (2017), 8010 - 8017

3 A. Kaiser, S. P. Foghmoes, G. Pećanac, J. Malzbender, C. Chatzichristodoulou, J. A. Glasscock, D. Ramachandran, D. W. Ni, V. Esposito, M. Søgaard and P. V. Hendriksen, 
Design and optimization of porous ceramic supports for asymmetric ceria-based oxygen transport membranes, Journal of Membrane Science vol. 513 (2016) p. 85 - 94

4 P. Kountouros, R. Förthmann, A. Naoumidis, G. Stochniol and E. Syskakis, Synthesis, forming and characterization of ceramic materials for the planar solid oxide fuel cell (SOFC), lonics, vol. 1 (1995) p. 40 - 50

5 R. Moreno, The Role of Slip Additives in Tape Casting Technology: Part I - Solvents and Dispersant, American Ceramic Society bulletin, vol. 71 (1992) p. 1521 - 1531

6 R. Moreno, The Role of Slip Additives in Tape Casting Technology: Part II - Binders and Plasticizers, American Ceramic Society bulletin, vol. 71 (1992) p. 1647 - 1657

7 J. Gurauskis, C. Baudín, A. J. Sánchez-Herencia, Tape casting of Y-TZP with low binder content, Ceramics International, Vol. 33 (2007) p. 1099 - 1103

8 M. P. Albano, L. A. Genova, L. B. Garrido and K. Plucknett, Processing of porous yttriastabilized zirconia by tape-casting, Ceramics International, Vol. 34 (2008) p. 1983 1988

9 C. G. Schmidt, K. K. Hansen, K. B. Andersen, Z. Fu, A. Roosen and A. Kaiser, Effect of pore formers on properties of tape cast porous sheets for electrochemical flue gas purification, Journal of the European Ceramic Society, Vol. 36 (2016) p. 645 - 653

10G. S. Lewis, A. Atkinson and B. C. H. Steele, Cobalt additive for lowering the sintering temperature of yttria-stabilized zirconia, Journal of Materials Science Letters vol. 20 (2001) p. $1155-1157$

11P. Satardekar, D. Montinaro and. V. M. Sglavo, Fe-doped YSZ electrolyte for the fabrication of metal supported-SOFC by co-sintering, Ceramics International, vol. 41 (2015) p. 9806 - 9812

12P. C. Hidber, T. J. Graule and L. J. Gauckler, Competitive Adsorption of Citric Acid and Poly(Vinyl Alcohol) onto Alumina and its Influence on the Binder Migration During Drying, Journal of the American Ceramic Society, vol. 78 (1995) p. 1775 - 1780

13K. Blackman, R. M. Slilaty and J. A. Lewis, Competitive Adsorption Phenomena in Nonaqueous Tape Casting Suspensions, Journal of the American Ceramic Society, vol. 84 (2001) p. 2501 - 2506

14S. Foghmoes, F. Teocoli, K. Brodersen, T. Klemensø and M. Della Negra, Novel ceramic processing method for substitution of toxic plasticizers, Journal of the European Ceramic Society, vol. 36 (2016) p. 3441 - 3449 
15K. Prabhakaran, A. Narayanan and C. Pavithran, Cardanol as a Dispersant Plasticiser for an Alumina/Toluene Tape Casting Slip, Journal of The European Ceramic Society, vol. 21 (2001) p. 2873 - 2878

16M. R. B. Romdhane, T. Chartier, S. Baklouti, J. Bouaziz, C. Pagnoux and J.-F. Baumard, A new processing aid for dry-pressing: A copolymer acting as dispersant and binder, Journal of The European Ceramic Society, vol. 27 (2007) p. 2687 - 2695

17M. Aslan, D. Weingarth, N. Jackel, J. S. Atchison, I. Grobelsek and V. Presser, Polyvinylpyrrolidone as Binder for Castable Supercapacitor Electrodes with High Electrochemical Performance in Organic Electrolytes, Journal of Power Sources, vol. 266 (2014) p. 374 - 383

18S. Bhattacharjee, M. K. Paria and H. S. Maiti, Polyvinyl Butyral as a Dispersant for Barium Titanate in a Non-aqueous Suspension, Journals of Materials Science, vol. 28 (1993) p. 6490 - 6495

19S. B. Reddy and P. P. Singh, Effect of Type of Solvent and Dispersant on Nano PZT Powder Dispersion for Tape Casting Slurry, Journal of Materials Science, vol. 37 (2002) p. 929 - 934

20T. Klemensø, M. Menon and S. Ramousse, Low Toxicity Binder Systems for Tape Cast Ce ${ }_{0.9} G_{0} d_{0.1} \mathrm{O}_{1.95}$ Laminates, Ceramics International, vol. 36 (2010) p. 773 - 780

21R. E. Mistler, E. Bianchi, B. Wade, J. Hurlbut, Evaluation of an environmentally friendly plasticizer for polyvinyl butyral for use in tape casing. In T. Ohji, M. Singh, J. Salem and D. Zhu, editors. Advanced processing and manufacturing technologies for structural and multifunctional materials: Ceramic engineering and science procedings, volume 28 . John Wiley and sons Inc., 2009, p. 27 - 34.

22R. E. Mistler, E. Bianchi and W. McNamee, Evaluation of Pycal 94 as an environmentally friendly plasticizer for polyvinyl butyral for use in tape casing. In $\mathrm{J}$. Matyâs, T. Ohji, X. Liu, M. P. Paranthaman, R. Devanathan, K. Fox, M. Singh and W. Wong-Ng, editors. Advances in Materials Science for Environmental and Energy Technologies II: Ceramic Transactions, Volume 241 John Wiley and sons Inc., 2013, p. $191-198$.

23J. Zhu, X. Li, C. Huang, L. Chen and L. Li, Plasticization Effect of Triacetin on Structure and Properties of Starch Ester Film, Carbohydrate Polymers vol. 94 (2013) p. 874 - 881

24R. Quintana, O. Persenaire, Y. Lemmouchi, J. Sampson, S. Martin, L. Bonnaud and P. Dubois, Enhancement of Cellulose Acetate Degradation under Accelerated Weathering 
by Plasticization with Eco-friendly Plasticizers, Polymer Degradation and Stability, vol. 98 (2013) p. 1556 - 1562

25M. A. Shirai, M. V. E. Grossmann, S. Mali, F. Yamashita, P. S. Garcia, C. M. O. Müller, Development of Biodegradable Flexible Films of Starch and Poly(lactic acid) Plasticized with Adipate or Citrate Esters, Carbohydrate Polymers, vol. 92 (2013) p. $19-22$

26P. C. Hidber, T. J. Graule and L. J. Gauckler, Citric Acid - A Dispersant for Aqueous Alumina Suspensions, Journal of the American Ceramic Society, vol. 79 (1996) p. 1857 $-1867$

27D. Hanaor, M. Michelazzi, C. Leonelli and C. C. Sorrell, The Effect of Carboxylic Acids on the Aqueous Dispersion and Electrophoretic Deposition of $\mathrm{ZrO}_{2}$, Journal of The European Ceramic Society, vol. 32 (2012) p. 235 - 244

28J. Elmore, G. Roy, E. Zylla, Citric ester diluents, EP 0361789, 1989

29Benckiser Gmbh Joh A, Mittel zur Verhinderung des Absetzens von Pigmenten in Ölund Lackanstrichmitteln, DE 1228736, 1959

30Richard E. Mistler, Eric R. Twiname, Tape casting Theory and Practice, John Wiley \& Sons, 1. Edition March 2006

31A. E. Levis, Polar-Screen Theory for the Deflocculation of Suspensions, Journal of the American Ceramic Society, vol. 44 (1961) p. 233 - 239

32P. Calvert, R. Lalanandham, M. Parish and E. Tormey, Dispersants in Ceramic Processing, British Ceramic Proceedings, (1986) p. 249 - 253

33S. Mizuta, M. Parish and H. K. Bowen, Dispersion of BaTiO3 Powders (Part I), Ceramics International, vol. 10 (1984) p. 43 - 48

34P. C. Hidber, T. J. Graule and L. J. Gauckler, Influence of the Dispersant Structure on Properties of Electrostatically Stabilized Aqueous Alumina Suspensions, Journal of the European Ceramic Society, vol. 17 (1997) p. 239 - 249

35J. Kastner, D. G. Cooper, M. Marić, P. Dodd and V. Yargeau, Aqueous leaching of di-2ethylhexyl phthalate and "green" plasticizers from poly(vinyl chloride), Science of the Total Environment, vol. 432 (2012) p. 357 - 364

36A. Ullah, T. Vasanthan, D. Bressler, A. L. Elias and J. Wu, Bioplastics from Feather Quill, Biomacromolecules, vol. 12 (2011) p. 3826 - 3832

37M. Della Negra, S. Foghmoes and T. Klemensø, Complementary analysis techniques applied on optimizing suspensions of yttria stabilized zirconia, Ceramics International, vol. 42 (2016) p. $14443-14451$ 
38C. M. Keck and R. H. Müller, Size analysis of submicron particles by laser diffractometry - $90 \%$ of the published measurements are false, International Journal of Pharmaceutics, 355 (2008) p. 150 - 163

39S Canovic, T Jonsson and M Halvarsson, Grain contrast imaging in FIB and SEM, Journal of Physics: Conference Series, vol. 126 (2008), 012054

40https://echa.europa.eu/da/brief-profile/-/briefprofile/100.001.416 (Last accessed 9.2.18)

41 http://echa.europa.eu/web/guest/candidate-list-table (Last accessed 9.2.18)

42https://echa.europa.eu/authorisation-list (Last accessed 9.2.18)

43https://echa.europa.eu/substance-information/-/substanceinfo/100.000.410 accessed 9.2.18)

44https://echa.europa.eu/substance-information/-/substanceinfo/100.007.898 accessed 9.2.18)

45https://echa.europa.eu/substance-information/-/substanceinfo/100.000.970 accessed 9.2.18)

46https://echa.europa.eu/brief-profile/-/briefprofile/100.002.775 (Last accessed 9.2.18)

47https://echa.europa.eu/brief-profile/-/briefprofile/100.000.974 (Last accessed 9.2.18)

48https://echa.europa.eu/brief-profile/-/briefprofile/100.000.975 (Last accessed 9.2.18)

49https://echa.europa.eu/brief-profile/-/briefprofile/100.000.971 (Last accessed 9.2.18)

$50 \mathrm{M}$. Z. Fiume, Final Report on the Safety Assessment of Triacetin, International International Journal of Toxicology, vol. 22 sup. 2 (2003) p. 1 - 10

51W Johnson, Final Report on the Safety Assessment of Trilaurin, Triarachidin, Tribehenin, Tricaprin, Tricaprylin, Trierucin, Triheptanoin, Triheptylundecanoin, Triisononanoin, Triisopalmitin, Triisostearin, Trilinolein, Trimyristin, Trioctanoin, Triolein, Tripalmitin, Tripalmitolein, Triricinolein, Tristearin, Triundecanoin, Glyceryl Triacetyl Hydroxystearate, Glyceryl Triacetyl Ricinoleate, and Glyceryl Stearate Diacetate, International Journal of Toxicology, vol. 20 sup. 4 (2001) p. 61 - 94

52M. M. Fiume, B. A. Heldreth, W. F. Bergfeld, D. V. Belsito, R. A. Hill, C. D. Klaassen, D. C. Liebler, J. G. Marks Jr, R. C. Shank, T. J. Slaga, P. W. Snyder and F. A. Andersen, Safety Assessment of Citric Acid, Inorganic Citrate Salts, and Alkyl Citrate Esters as Used in Cosmetics, International Journal of Toxicology, vol. 33 sup. 2 (2014) p. $16 S$ $46 \mathrm{~S}$

53W. Johnson, Final Report on the Safety Assessment of Acetyl Triethyl Citrate, Acetyl Tributyl Citrate, Acetyl Trihexyl Citrate, and Acetyl Trioctyl Citrate, International Journal of Toxicology, vol. 21 sup. 2 (2002) p. 1 - 17 
54G. Wang, P. Sarkar, P. S. Nicholson, Influence of acidity on the electrostatic stability of alumina suspensions in ethanol, Journal of the American Ceramic Society, vol. 80 (1997) p. 965 - 972 